\title{
Divalent metal inhibition of non-haem iron uptake across the rat duodenal brush border membrane
}

\author{
Michael W. Smith ${ }^{1}$, K. Bhasker Shenoy ${ }^{1}$, Edward S. Debnam ${ }^{1}$, Michael R. Dashwood ${ }^{2}$, \\ Linda J. Churchill ${ }^{1}$ and S. Kaila Srai ${ }^{3}$ \\ Epithelial Transport Laboratories, Departments of ${ }^{1}$ Physiology, and ${ }^{2}$ Chemical Pathology, ${ }^{3}$ Biochemistry and Molecular \\ Biology, Royal Free and University College Medical School, London, UK
}

(Received 15 August 2001 - Revised 3 January 2002 - Accepted 7 February 2002)

\begin{abstract}
Duodenal $\mathrm{Fe}^{2+}$ uptake is essential to body $\mathrm{Fe}^{2+}$ homeostasis, but the interaction of metals with the uptake process remains unclear. The present study compared the effects of four essential trace metals $\left(\mathrm{Mn}^{2+}, \mathrm{Zn}^{2+}, \mathrm{Co}^{2+}\right.$ and $\left.\mathrm{Ni}^{2+}\right)$ with two toxic metals $\left(\mathrm{Pb}^{2+}\right.$ and $\left.\mathrm{Cd}^{2+}\right)$ on $\mathrm{Fe}^{2+}$ uptake across the brush border membrane of villus-attached duodenal enterocytes. Everted rat duodenum was exposed to buffer containing $0.2 \mathrm{mM}^{-59} \mathrm{Fe}^{2+}$-ascorbate with or without the competing metal $(2 \mathrm{mM})$ and the tissue was then processed for autoradiography allowing $\mathrm{Fe}^{2+}$ uptake to be determined at specific crypt-villus regions. The quantification method ensured that uptake by cells, rather than $\mathrm{Fe}^{2+}$ binding to the tissue surface, was measured. $\mathrm{Fe}^{2+}$ uptake was significantly inhibited by $\mathrm{Cd}^{2+}$ in upper villus enterocytes only and $\mathrm{Pb}^{2+}$ was without effect on $\mathrm{Fe}^{2+}$ uptake. The inhibition by $\mathrm{Cd}^{2+}$ was not due to general cell damage as judged by the release of lactate dehydrogenase from tissue into incubation fluid. Essential divalent trace metals reduced uptake significantly along the whole length of the crypt-villus axis. $\mathrm{Cd}^{2+}$ uptake, measured separately, took place at all regions of the villuscrypt axis, highest uptake being into crypt enterocytes. The very different uptake profiles for $\mathrm{Cd}^{2+}$ and $\mathrm{Fe}^{2+}$ suggests that the divalent metal transporter 1 is not the principal transporter of $\mathrm{Cd}^{2+}$. The addition of $\mathrm{Fe}^{2+}$ to incubation buffer inhibited $\mathrm{Cd}^{2+}$ uptake by both crypt and villus enterocytes. The possibility that the inhibitory actions of $\mathrm{Fe}^{2+}$ and $\mathrm{Cd}^{2+}$ on the uptakes of $\mathrm{Cd}^{2+}$ and $\mathrm{Fe}^{2+}$ respectively can be explained by a non-competitive action or the involvement of an additional metal transporter is discussed.
\end{abstract}

Intestinal iron transport: Duodenum: Cadmium uptake: Brush border membrane

The absence of a mechanism for controlling $\mathrm{Fe}^{2+}$ excretion makes the process for uptake of the metal across the intestine crucial to body iron homeostasis. The level of dietary $\mathrm{Fe}^{2+}$ influences duodenal uptake of $\mathrm{Fe}^{2+}$ (Charlton \& Bothwell, 1983; Smith et al. 2000) and although the response is thought to alter the expression of the divalent metal transporter (DMT) 1 at the brush border membrane (BBM) (Oates et al. 2000; Trinder et al. 2000) the mechanisms involved remain poorly understood. Essential trace metals also affect $\mathrm{Fe}^{2+}$ uptake in predictable ways (Rucker et al. 1994) and studies using Xenopus oocytes expressing DMT1 have implied that interactions of divalent trace metals with $\mathrm{Fe}^{2+}$ uptake take place through competition for DMT1 (Gunshin et al. 1997). This situation is however complicated by the fact that DMT1 may also transport $\mathrm{Cd}^{2+}$ and $\mathrm{Pb}^{2+}$ (Andrews et al. 1999; Tallkvist et al. 2001), metals which are highly toxic and chemically distinct from the other essential trace metals (Frausto da Silva \& Williams, 1991). We therefore considered it worthwhile to compare and analyse the ability of $\mathrm{Cd}^{2+}$ and $\mathrm{Pb}^{2+}$, as well as essential trace metals, to inhibit $\mathrm{Fe}^{2+}$ uptake by intact duodenal mucosa. Since uptake of $\mathrm{Fe}^{2+}$ across the BBM and expression of DMT1 follow a similar developmental profile along the villus (O'Riordan et al. 1995; Trinder et al. 2000), autoradiographic methods were used to determine $\mathrm{Fe}^{2+}$ uptake across the BBM at specific loci along the villus axis. Care was taken to ensure that our autoradiographic method was a measure of $\mathrm{Fe}^{2+}$ uptake across the brush border, rather than binding of the metal to the mucosal surface.

The aims of the present study were to demonstrate the importance of using intact duodenal epithelium as a

Abbreviations: BBM, brush border membrane; DMT1, divalent metal transporter 1; LDH, lactate dehydrogenase.

* Corresponding author: Dr Edward S. Debnam, fax +44 207433 1921, email esdeb@rfc.ucl.ac.uk 
useful model for assessing both the manner in which $\mathrm{Fe}^{2+}$ crosses the intestine and the way in which other important trace metals might affect $\mathrm{Fe}^{2+}$ absorption. A short account of this work has been published previously (Shenoy et al. 2001).

\section{Materials and methods}

\section{Chemicals}

${ }^{59} \mathrm{FeCl}_{3}$ and ${ }^{109} \mathrm{CdCl}_{2}$ were obtained from NEN Life Science Products (Hounslow, Middlesex, UK). All other chemicals were of Analar Grade from Sigma Limited (Poole, Dorset, UK) or Merck Limited (Poole, Dorset, UK).

\section{Iron and cadmium uptake}

All experiments were carried out in accordance with the UK Animals (Scientific Procedures) Act 1986. The method used to measure $\mathrm{Fe}^{2+}$ uptake was similar to that described previously (O'Riordan et al. 1995; Smith et al. 2000). Briefly, it involved removing duodenal tissue from Sprague-Dawley rats $(230-250 \mathrm{~g})$, anaesthetized with pentobarbitone sodium ( $90 \mathrm{mg} / \mathrm{kg}$, intraperitoneal), and everting the tissue before dividing it into two equal lengths. One of these was stored in cooled saline whilst the other was pre-incubated for $5 \mathrm{~min}$ in oxygenated buffer, $\mathrm{pH} 7 \cdot 1$ (mM: Hepes 16, glucose $10, \mathrm{KCl} 3 \cdot 5, \mathrm{MgSO}_{4} 10, \mathrm{CaCl}_{2}$ $1, \mathrm{NaCl} 125)$ followed by $5 \mathrm{~min}$ incubation in buffer containing $0.2 \mathrm{mM}^{59} \mathrm{Fe}^{2+}$ (complexed with $4 \mathrm{mM}$ ascorbic acid; ${ }^{59} \mathrm{Fe}^{2+}$ specific activity $0.52 \mathrm{MBq} / \mathrm{ml}$ ), with or without the competing metal ( $2 \mathrm{mM})$. Previous studies using Caco-2 cells have shown that a buffer $\mathrm{pH}$ range of $6 \cdot 5-7 \cdot 1$ is appropriate for $\mathrm{Fe}^{2+}$ uptake (Worthington et al. 2000), that $0.2 \mathrm{mM}$ is an appropriate concentration for measurement of $\mathrm{Fe}^{2+}$ uptake (Cox \& Peters, 1980; Raja et al. 1987) and that $\mathrm{Fe}^{2+}$ entry into duodenal tissue increases linearly with time for up to 10 min (Cox \& Peters, 1979; Raja et al. 1989). The stored tissue was then taken through the same two incubation procedures. The order in which tissues were incubated with ${ }^{59} \mathrm{Fe}^{2+}$ alone or with the competing metal was alternated to avoid possible effects of a 10 min storage time on $\mathrm{Fe}^{2+}$ uptake. Subsequent washing of the tissues to displace surface-bound $\mathrm{Fe}$ and fixation and processing of the tissues for autoradiography was carried out as described previously (O'Riordan et al. 1995; Smith et al. 2000). The uptake of $0.2 \mathrm{~mm}$ along the villus and the effects of $2 \mathrm{mM}-\mathrm{Fe}^{2+}$ in the incubation buffer were measured using an identical uptake method, again utilizing paired tissue sections.

\section{Quantitation of metal uptake}

$\mathrm{Fe}^{2+}$ uptake was assessed by autoradiography using a Vanox AH-2 microscope (Olympus, London, UK) at a final magnification of $\times 4000$ to detect Ag grains under dark field illumination through a photoelectric cell built into the microscope. Under these conditions Ag grains on autoradiographs were easily identified as separate spots of light. Fainter, non-specific light present in sectioned tissue was largely eliminated by closing the iris and passing emitted light through a light balancing daylight filter before recording the light intensity as an exposure time determined automatically by the apparatus. Measurements of light intensity used a scanning spot of $25 \mu \mathrm{m}$ diameter placed manually over the cytosolic region of enterocytes at different positions along the crypt-villus axis of sectioned villi. Single readings of light intensity were taken for each region of the villus. These readings were however taken from three villi per animal. Inter-villus variation in exposure time ranged from 7.8 to $14.8 \mathrm{~s}$ in the tips of these villi. This variation was substantially reduced $(9.5$ to $11.5 \mathrm{~s}$ ) by taking mean values obtained by analysing tissue from six animals.

The validity of this quantitative method was assessed separately by comparing exposure times with counts of Ag grains carried out directly on enlarged photographs of the same areas of villi. Results showed a linear relation between the increase in grain counts and a decrease in exposure time from 19 to $5 \mathrm{~s}$ (results not shown). The negative slope of this graph $(-7.2$ grains/s exposure time) then allowed the conversion of exposure times to $\mathrm{Ag}$ grain counts and thus the quantitation of $\mathrm{Fe}^{2+}$ uptake. The advantage of this method compared with microdensitometry was that it shortened considerably the time needed to determine uptake in selected areas of the villus. This was particularly important in the present work that involved taking measurements from villi obtained from a large number of rats.

\section{Microdensitometry}

The use of microdensitometry to determine the positional location of transporter expression along villi has already been described in detail (Smith et al. 2000). Briefly, it involves routine preparation of autoradiographs of sectioned villi that are then scanned manually using an M85 microdensitometer (Vickers, Pudsey, UK). Readings of optical density are taken sequentially from crypt to villus tip. The final information obtained is sufficiently detailed to detect minor changes in the expression of transport function.

\section{Lactate dehydrogenase activity}

The pre-incubation and incubation protocols used were similar to those described for measurement of $\mathrm{Fe}^{2+}$ uptake. However, only the bottom half of everted U-shaped intestinal segments were immersed in buffer in order to ensure that the cut ends of the segment could not release lactate dehydrogenase (LDH) into the buffer. $\mathrm{LDH}$ activity was measured after exposure to buffer, with or without $2 \mathrm{mM}-\mathrm{Cd}^{2+}$, using a commercial assay kit (Sigma).

\section{Statistics}

Mean values with their standard errors for $\mathrm{Fe}^{2+}$ uptake were calculated by analysis of three villi from each of six rats. Mean values with their standard errors for $\mathrm{Cd}^{2+}$ uptake were calculated by analysis of three villi taken from each of eight rats. Differences between means were 
evaluated using the paired Student's $t$ test. Values of $P>0.05$ were considered to be not significantly different.

\section{Results}

\section{Divalent metal inhibition of iron transport}

Results showing the ability of five different divalent metals to inhibit $\mathrm{Fe}^{2+}$ uptake at four different locations along sectioned duodenal villi are given in Fig. 1. In the absence of competing metal, $\mathrm{Fe}^{2+}$ uptake more than doubled as enterocytes migrated from crypts through to the lower villus. This increased uptake then continued until enterocytes reached the mid-villus but no further change in transport occurred during subsequent enterocyte migration. A virtually identical developmental profile for $\mathrm{Fe}^{2+}$ transport was recorded in the presence of $\mathrm{Cr}^{3+}$, a finding that supports results obtained
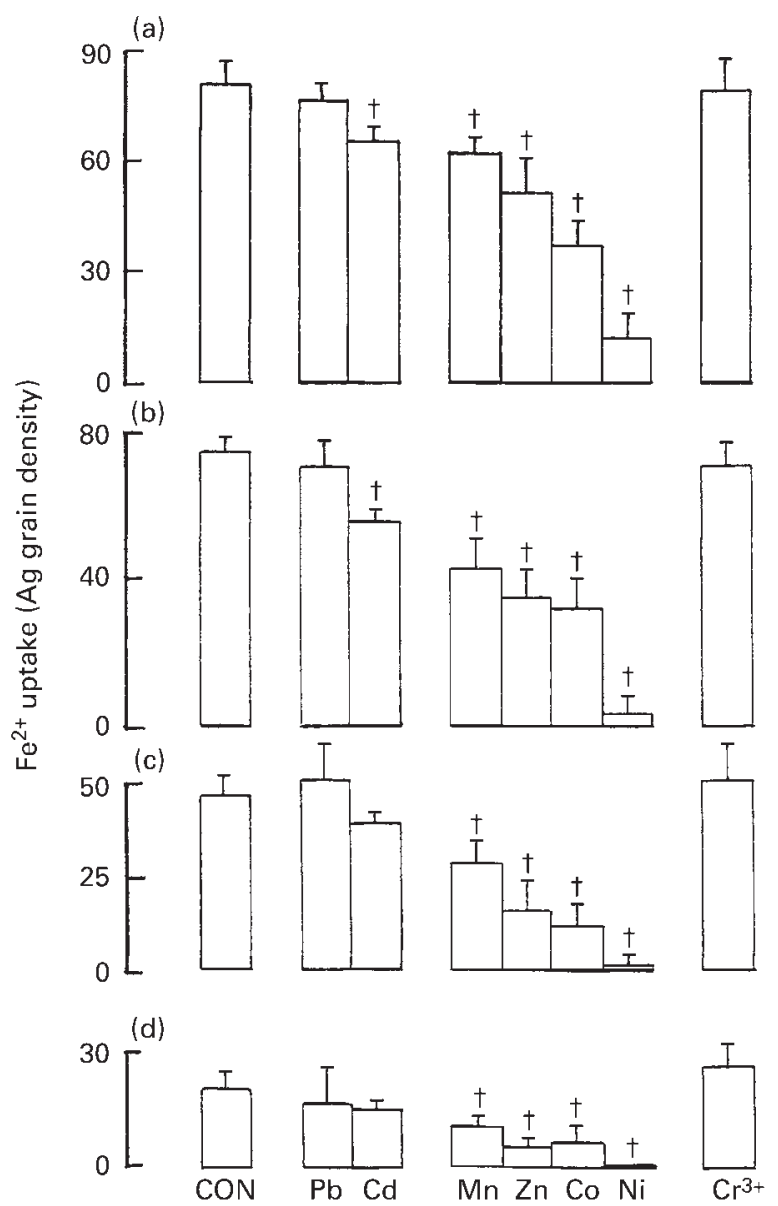

Fig. 1. Divalent metal inhibition of $\mathrm{Fe}^{2+}$ uptake by rat duodenum. Everted duodenum was incubated for $5 \mathrm{~min}$ with $0.2 \mathrm{~mm}^{-59} \mathrm{Fe}^{2+}$ with or without $2 \mathrm{~mm}$ of the non-radioactive competing metal. Tissues were later processed to produce autoradiographs of sectioned villi and $\mathrm{Fe}^{2+}$ uptakes were determined by $\mathrm{Ag}$ grain counts of the enterocyte cytosolic region at different positions along the crypt-villus axis. (a), Tip; (b), mid; (c), base; (d), crypt. The villus base, mid-villus and villus tip represent areas 25, 50 and $80 \%$ respectively from the crypt-villus junction. Values are means with standard errors shown by vertical bars. The control value (CON) is the mean $(n 42)$ for $\mathrm{Fe}^{2+}$ uptake determined in the absence of competing metal. Mean values were significantly different from control values: $\dagger P<0.05$ to $P<0.001$. from oocytes showing that only divalent metals are transported by DMT1 (Gunshin et al. 1997).

Differences were, however, seen between the ability of various divalent metals to inhibit $\mathrm{Fe}^{2+}$ uptake. Results for the mid-villus (Fig. 1) show for example that mean inhibitions of $\mathrm{Fe}^{2+}$ uptake using tissue from six rats to be as follows (\%): $\mathrm{Cd}^{2+} 18 \cdot 0, \mathrm{Mn}^{2+} 26 \cdot 0, \mathrm{Zn}^{2+} 42 \cdot 8, \mathrm{Co}^{2+} 53 \cdot 2, \mathrm{Ni}^{2+}$ 87.8. $\mathrm{Pb}^{2+}$ was unable to inhibit $\mathrm{Fe}^{2+}$ uptake significantly at any of the four villus regions implying that uptake of $\mathrm{Pb}^{2+}$ across the BBM, like $\mathrm{Cr}^{3+}$, does not utilize the DMT1 transporter.

The statistical significance of the remaining differences seen between control and test measurements of $\mathrm{Fe}^{2+}$ uptake were assessed using the paired $t$ test. All divalent metals tested, apart from $\mathrm{Pb}^{2+}$, caused significant inhibition of $\mathrm{Fe}^{2+}$ uptake. Further paired $t$ tests carried out on uptake data using other regions of the villus and crypts showed $\mathrm{Mn}^{2+}, \mathrm{Zn}^{2+}, \mathrm{Co}^{2+}$ and $\mathrm{Ni}^{2+}$ to cause significant inhibition of $\mathrm{Fe}^{2+}$ uptake. Inhibition by $\mathrm{Cd}^{2+}$ was, however, only statistically significant at the upper half of the villus whilst $\mathrm{Pb}^{2+}$ remained unable to inhibit $\mathrm{Fe}^{2+}$ uptake at any of the crypt and villus locations tested. These results provide strong evidence against the involvement of DMT1 with respect to $\mathrm{Pb}^{2+}$ uptake. The case for DMT1-mediated $\mathrm{Cd}^{2+}$ uptake, however, required further investigation.

\section{Cadmium-iron interactions along duodenal villi}

The profile describing increasing $\mathrm{Fe}^{2+}$ uptake during enterocyte migration along villi is already well documented (O'Riordan et al. 1995; Smith et al. 2000), but no comparable results exist for $\mathrm{Cd}^{2+}$ uptake along the crypt-villus axis. Experiments using ${ }^{59} \mathrm{Fe}^{2+}$ and ${ }^{109} \mathrm{Cd}^{2+}$ were therefore carried out to compare directly the uptake profiles of the two metals. The results obtained are shown in Fig. 2.

Crypt enterocytes displayed the highest uptake of $\mathrm{Cd}^{2+}$ cells at the upper villus having about half the rate of $\mathrm{Cd}^{2+}$ uptake compared with those in the crypt. In contrast, the profile for $\mathrm{Fe}^{2+}$ uptake showed lowest uptake in the crypt region and highest uptake in the upper villus region (Fig. 2). These results confirm results from measurements taken in four different regions along the crypt-villus axis (control values, Fig. 1).

The shape of the profile for $\mathrm{Fe}^{2+}$ uptake corresponds with that shown for DMT1 expression (Trinder et al. 2000). However, the very different profile for $\mathrm{Cd}^{2+}$ uptake along the crypt-villus axis indicates that the predominant mode of entry of this metal is not DMT1-dependent.

$$
\mathrm{Fe}^{2+} \text { inhibition of } \mathrm{Cd}^{2+} \text { uptake }
$$

A final test of whether some $\mathrm{Cd}^{2+}$ entry into upper villus enterocytes might still take place through DMT1 involved comparing profiles for $\mathrm{Cd}^{2+}$ uptake in the absence and presence of $2 \mathrm{mM}-\mathrm{Fe}^{2+}$. Localized inhibition of $\mathrm{Cd}^{2+}$ in upper villus enterocytes in the presence of $\mathrm{Fe}^{2+}$ would, in this case, support the view that $\mathrm{Cd}^{2+}$ entry was DMT1mediated.

$\mathrm{Fe}^{2+}$ inhibited $\mathrm{Cd}^{2+}$ uptake by 40 to $50 \%$ along the entire villus axis (Fig. 3) including those regions of the villus known to be deficient in DMT1. These results therefore 


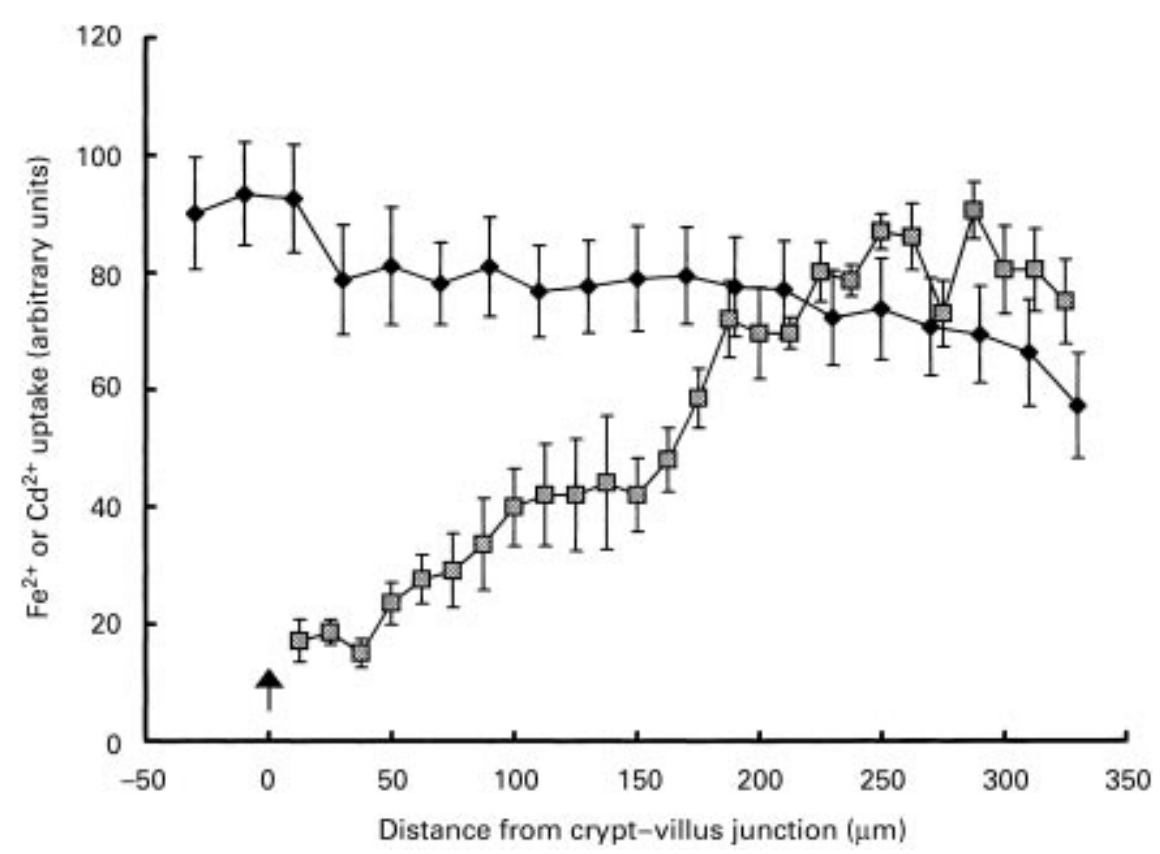

Fig. 2. Positional distribution of $\mathrm{Fe}^{2+}\left(\right.$ 圆) and $\mathrm{Cd}^{2+}(\diamond)$ uptake along rat duodenal villi. For details of procedures, see p. 52. Values are means for uptake of the metal determined by the measurement of $\mathrm{Ag}$ grain density in the cytosolic region of enterocytes, with standard errors shown by vertical bars. Villus length was $390 \mu \mathrm{m}$. $\uparrow$, Crypt-villus junction.

provide some evidence for DMT1-independent $\mathrm{Cd}^{2+}$ transport taking place across the duodenal BBM.

\section{Lactate dehydrogenase release}

Determination of LDH activity in incubation buffer was carried out in order to test whether inhibition of $\mathrm{Fe}^{2+}$ uptake by $\mathrm{Cd}^{2+}$ was a consequence of non-specific damage to enterocyte function. Incubation of everted duodenum did not affect $\mathrm{LDH}$ release $\left(-\mathrm{Fe}^{2+} 0.029\right.$ (SEM 0.007), $+\mathrm{Fe}^{2+} 0.023$ (SEM 0.006) U/g tissue per min, $n 5$ pairs, $P=0 \cdot 19)$. Surprisingly, $\mathrm{Cd}^{2+}$ caused a sig-

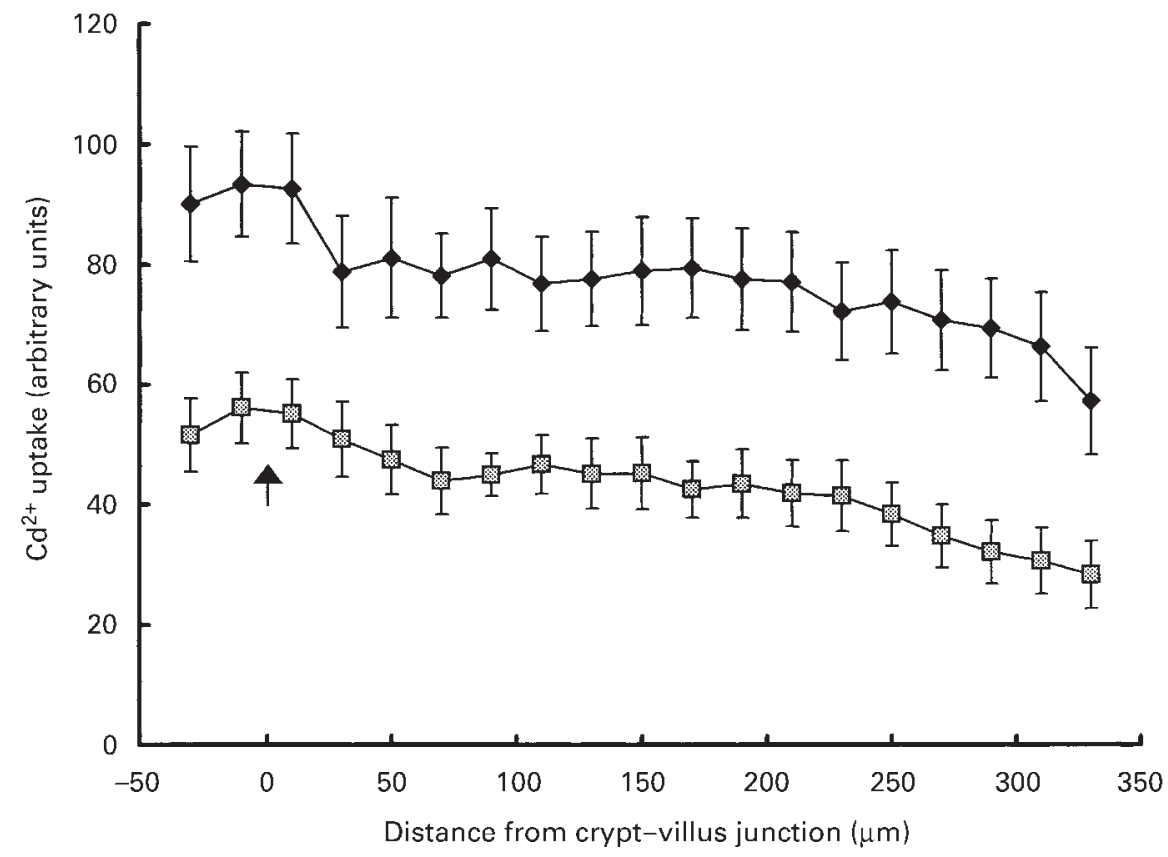

Fig. 3. Inhibition of $\mathrm{Cd}^{2+}$ uptake by $\mathrm{Fe}^{2+}$. Results show $\mathrm{Cd}^{2+}$ uptake by upper crypt to villus tip enterocytes with or without $2 \mathrm{mM}-\mathrm{Fe}^{2+}$ in the incubation buffer. $(\bullet), \mathrm{Fe}^{2+}$ absent; (圆), $\mathrm{Fe}^{2+}$ present. For details of procedures, see p. 52. Values are means with standard errors shown by vertical bars. Measurements were taken up to $330 \mu \mathrm{m}$ of a maximum villus length of $390 \mu \mathrm{m}$. $\uparrow$, Crypt-villus junction. Mean values for $\mathrm{Fe}^{2+}$ present were significantly different from those with $\mathrm{Fe}^{2+}$ absent at all points along the crypt-villus axis $(P<0.001)$. 
nificant decrease in LDH release $(64.7 \%, P=0.031, n 5)$. The possibility that this effect could be caused by a direct inhibitory action of the metal on LDH activity was investigated by measuring enzyme activity, with or without $2 \mathrm{mM} \mathrm{Cd}^{2+}$, in buffer collected after the initial $5 \mathrm{~min}$ preincubation with duodenum. The metal was found to be without effect on LDH activity $\left(-\mathrm{Cd}^{2+} 0.10\right.$ (SEM 0.03), $+\mathrm{Cd}^{2+} 0.10(\mathrm{SEM} 0.03) \mathrm{U} / \mathrm{g}$ tissue per min, $n 11$ pairs, $P=0 \cdot 7)$.

\section{Discussion}

$\mathrm{Fe}^{2+}$ is essential for many cellular processes and the absence of a regulatory process for excretion of the metal means that body $\mathrm{Fe}^{2+}$ homeostasis is crucially dependent on the rate of uptake of the metal across the small intestine (Charlton \& Bothwell, 1983). On the basis of expression studies using Xenopus oocytes, Gunshin et al. (1997) proposed that DMT1 is responsible for movement of $\mathrm{Fe}^{2+}$ across the duodenal BBM. Levels of DMT1 mRNA within duodenal enterocytes are influenced by dietary $\mathrm{Fe}^{2+}$ content (Oates et al. 2000; Trinder et al. 2000), implying that changes in gene expression of the transporter are involved in control of $\mathrm{Fe}^{2+}$ absorption in response to $\mathrm{Fe}^{2+}$ status. However, despite the apparent importance of DMT1 in body $\mathrm{Fe}^{2+}$ metabolism, there is conflicting information concerning the substrate specificity of this transporter.

Early literature describing interactions between divalent metals on their uptake across the small intestine reflect both the concern of nutritionists to ensure an optimal body balance of essential trace metals and the emphasis by toxicologists of the need to protect animals from the effects of metallic poisons. DMT1 has been reported to transport both essential non-toxic and toxic divalent metals across the membrane of DMT1 mRNA-primed oocytes (Gunshin et al. 1997) and to transport $\mathrm{Cd}^{2+}$ in Caco-2 cells (Tallkvist et al. 2001). Despite these studies, most studies of the role of DMT1 have tended to concentrate on the importance of the transporter in the control of body $\mathrm{Fe}^{2+}$ metabolism rather than its ability to absorb toxic heavy metals.

In attempting to broaden this interest in DMT1, it was first thought necessary to test whether DMT1-selectivity for divalent metals, established previously using oocytes, would also apply to villus-attached enterocytes, since the latter preparation is more physiologically relevant to the uptake of divalent metals under normal conditions. In the present study, inhibition of $\mathrm{Fe}^{2+}$ uptake by different divalent metals was initially taken to indicate the involvement of DMT1 in transport. Of the six divalent metals tested, only $\mathrm{Pb}^{2+}$ failed to inhibit $\mathrm{Fe}^{2+}$ transport. $\mathrm{Pb}^{2+}$ is nevertheless a toxic metal that is absorbed by the intestine and this has consequences for health (Ferguson, 1990).

The other toxic metal, $\mathrm{Cd}^{2+}$, only inhibited $\mathrm{Fe}^{2+}$ transport significantly at the upper villus region. Uptake of $\mathrm{Cd}^{2+}$ took place most readily in those regions of the villus containing the least amounts of DMT1 (see Fig. 2 for uptake and Trinder et al. (2000) for DMT1 expression). A final surprise was the finding that $\mathrm{Fe}^{2+}$ also inhibited $\mathrm{Cd}^{2+}$ uptake, this occuring to a similar extent at all levels along the crypt-villus axis, despite the fact that $\mathrm{Fe}^{2+}$ transport increases along the villus. All of these effects are not caused by toxic effects of $\mathrm{Cd}^{2+}$ on incubated intestine, as assessed by the failure of the metal to cause changes in efflux of LDH from the tissue.

Some of the these inconsistencies could be explained by the presence of additional metal transporters in the intestine. In testing for this, however, it would first be necessary to establish whether metal uptake followed MichaelisMenten saturation kinetics in order to distinguish between competitive and non-competitive mechanisms of inhibition. This has already been established for $\mathrm{Fe}^{2+}$ in oocytes (Gunshin et al. 1997) but not for $\mathrm{Cd}^{2+}, \mathrm{Mn}^{2+}$ and $\mathrm{Co}^{2+}$, each of which we have now shown to be inhibitors of $\mathrm{Fe}^{2+}$ transport through DMT1. It is particularly important to make this distinction for $\mathrm{Cd}^{2+}$ since this metal is known to inhibit the intestinal transport of $\mathrm{Ca}^{2+}$, threonine and galactose by non-competive means (Hamilton \& Smith, 1978; Mesonero et al. 1993, 1996). It remains reasonable, however, to assume that inhibition of intestinal $\mathrm{Cd}^{2+}$ uptake by $\mathrm{Fe}^{2+}$ could be either non-competitive or could involve a different transporter of $\mathrm{Fe}^{2+}$.

The ability of DMT1 to mediate the entry of a wide variety of divalent metals into Xenopus oocytes (Gunshin et al. 1997 ) is greater than that found previously for any other type of transporter. This non-selectivity has now been shown to be similar when measuring the ability of divalent cations to inhibit $\mathrm{Fe}^{2+}$ uptake by enterocytes (Fig. 1). Caco-2 cells, that express DMT1, also show a wide specificity profile for divalent metals, though many of the inhibitory effects on $\mathrm{Fe}^{2+}$ transport proved to be statistically insignificant (Tandy et al. 2000).

In conclusion, in an attempt to provide evidence that $\mathrm{Pb}^{2+}$ and $\mathrm{Cd}^{2+}$ do not enter intact enterocytes via DMT1, the present study has uncovered a new area of uncertainty about the ways in which divalent metals are transported across the duodenal BBM. Relating the uptake of a metal to its ability to act as an inhibitor and to relate both to the state of enterocyte differentiation appears generally to be a powerful way to test existing views of how different metals interact at the mucosal level.

\section{Acknowledgements}

We are grateful to the Commonwealth Office for support of Dr Bhasker Shenoy, and to Mr M. Adams for technical assistance.

\section{References}

Andrews NC, Fleming MD \& Gunshin H (1999) Iron transport across biological membranes. Nutrition Reviews 57, 114-123.

Charlton RW \& Bothwell TH (1983) Iron absorption. Annual Review of Medicine 34, 55-68.

Cox TM \& Peters TJ (1979) The kinetics of iron uptake in vivo by human duodenal mucosa: studies in normal subjects. Journal of Physiology 289, 469-478.

Cox TM \& Peters TJ (1980) In vitro studies of duodenal iron uptake in patients with primary and secondary iron storage disease. Quarterly Journal of Medicine 195, 249-257.

Ferguson JE (1990) The Heavy Metals: Chemistry, Environmental Impact and Health Effects. Oxford: Pergamon Press. 
Frausto da Silva JJR \& Williams RJP (1991) The Biological Chemistry of the Elements. Oxford: Clarendon Press.

Gunshin H, Mackenzie B, Berger UV, Gunshin Y, Romero MF, Boron WF, Nussberger S, Gollan JL \& Hediger MA (1997) Cloning and characterisation of a mammalian proton-coupled metal-ion transporter. Nature 388, 482-488.

Hamilton DL \& Smith MW (1978) Inhibition of intestinal calcium uptake by cadmium and the effect of a low cadmium retention. Environmental Research 15, 175-184.

Oates PS, Trinder D \& Morgan EH (2000) Gastrointestinal function, divalent metal transporter-1 expression and intestinal iron absorption. Pflügers Archiv European Journal of Physiology 440, 496-502.

O'Riordan DK, Sharp PA, Sykes RM, Srai SK, Epstein O \& Debnam ES (1995) Cellular mechanisms underlying the increased duodenal iron absorption in rats in response to phenylhydrazine-induced haemolytic anaemia. European Journal of Clinical Investigation 25, 722-727.

Mesonero JE, Rodriguez Yoldi MC \& Rodriguez Yoldi MJ (1993) Effect of cadmium on enzymic digestion and sugar transport in the small intestine of rabbit. Biological Trace Element Research 38, 217-226.

Mesonero JE, Rodriguez Yoldi MC \& Rodriguez Yoldi MJ (1996) Inhibition of L-threonine intestinal absorption in rabbits by cadmium. Biological Trace Element Research 52, 133-142. Raja KB, Simpson RJ \& Peters TJ (1987) Comparison of ${ }^{59} \mathrm{Fe}^{3+}$ uptake in vitro and in vivo by mouse duodenum. Biochimica et Biophysica Acta 901, 52-60.

Raja KB, Simpson RJ \& Peters TJ (1989) Membrane potential dependence of Fe(III) uptake by mouse duodenum. Biochimica et Biophysica Acta 984, 262-266.

Rucker RB, Lönnerdal B \& Keen CL (1994) Intestinal absorption of nutritionally important trace metals. In Physiology of the Gastrointestinal Tract, pp. 2183-2200 [LR Johnson, editor]. New York, NY: Raven Press.

Shenoy KB, Debnam ES, Srai SK, Dashwood MR, Churchill LJ \& Smith MW (2001) Testing the selectivity of DMT1 as a transporter of divalent metals into isolated rat duodenum. Journal of Physiology 533, 12P-13P.

Smith MW, Debnam ES, Dashwood MR \& Srai SK (2000) Structural and cellular adaptation of duodenal iron uptake in rats maintained on an iron-deficient diet. Pflügers Archiv European Journal of Physiology 439, 449-454.

Tallkvist J, Bowlus CL \& Lonnerdal B (2001) DMT1 gene expression and cadmium absorption in human absorptive enterocytes. Toxicology Letters 122, 171-177.

Tandy S, Williams M, Leggett A, Lopez-Jimenez M, Dedes M, Ramesh B, Srai SK \& Sharp PA (2000) Nramp2 expression is associated with $\mathrm{pH}$-dependent iron uptake across apical membrane of human intestinal Caco-2 cells. Journal of Biological Chemistry 275, 1023-1029.

Trinder D, Oates PS, Thomas C, Sadleir J \& Morgan EH (2000) Localisation of DMT1 to the microvillus membrane of rat duodenal enterocytes in iron deficiency but to hepatocytes in iron overload. Gut 46, 270-276.

Worthington MT, Browne L, Battle EH \& Qi Luo R (2000) Functional properties of transfected human DMT1 iron transporter. American Journal of Physiology 279, G1265-G1273. 